\title{
Bioactivities of Traditional Medicinal Plants in Alexandria
}

\author{
Hosam O. Elansary $\mathbb{D}^{1,2}$ Agnieszka Szopa, ${ }^{3}$ Paweł Kubica, ${ }^{3}$ \\ Halina Ekiert, ${ }^{3}$ Hayssam M. Ali ${ }^{1},{ }^{4,5}$ Mohamed S. Elshikh, ${ }^{4}$ Eslam M. Abdel-Salam, ${ }^{4}$ \\ Mohamed El-Esawi $\mathbb{D}^{6}{ }^{6}$ and Diaa O. El-Ansary ${ }^{7}$ \\ ${ }^{1}$ Floriculture, Ornamental Horticulture and Garden Design Department, Faculty of Agriculture (El-Shatby), \\ Alexandria University, Alexandria, Egypt \\ ${ }^{2}$ Department of Geography, Environmental Management and Energy Studies, University of Johannesburg, APK Campus, \\ 2006, South Africa \\ ${ }^{3}$ Department of Pharmaceutical Botany, Medical College, Jagiellonian University, Ul. Medyczna 9, 30-688 Kraków, Poland \\ ${ }^{4}$ Botany and Microbiology Department, College of Science, King Saud University, P.O. Box 2455, Riyadh 11451, Saudi Arabia \\ ${ }^{5}$ Timber Trees Research Department, Sabahia Horticulture Research Station, Horticulture Research Institute, \\ Agriculture Research Center, Alexandria, Egypt \\ ${ }^{6}$ Botany Department, Faculty of Science, Tanta University, Tanta, Egypt \\ ${ }^{7}$ Precision Agriculture Laboratory, Department of Pomology, Faculty of Agriculture (El-Shatby), \\ Alexandria University, Alexandria, Egypt
}

Correspondence should be addressed to Hayssam M. Ali; hayhassan@ksu.edu.sa

Received 27 November 2017; Accepted 4 January 2018; Published 31 January 2018

Academic Editor: Letizia Angiolella

Copyright ( $\odot 2018$ Hosam O. Elansary et al. This is an open access article distributed under the Creative Commons Attribution License, which permits unrestricted use, distribution, and reproduction in any medium, provided the original work is properly cited.

In traditional folklore, medicinal herbs play a vital role in the prevention and treatment of microbial diseases. In the present study, the phenolic profiles of the medicinal plants Asparagus aethiopicus L., Citrullus colocynthis L., Senna alexandrina L., Kalanchoe delagoensis L., Gasteria pillansii L., Cymbopogon citratus, Brassica juncea, and Curcuma longa L. were determined by highperformance liquid chromatography with a diode-array detector method. The results revealed rich sources of important compounds such as robinin in the fruits and leaves of A. aethiopicus; caffeic acid in the tubers of A. aethiopicus and quercitrin in the leaves of G. pillansii. Further, relatively high antioxidant, antibacterial, and antifungal activities were observed in C. colocynthis fruit coat, $S$. alexandrina pods, and $A$. aethiopicus leaves, respectively. The relatively higher the bioactivities of plants extracts associated with the phenols in these plants, in particular, the more abundant the phenols. Therefore, it was concluded that the fruit coat of $C$. colocynthis, pods of S. alexandrina, and leaves of A. aethiopicus might be excellent sources of natural products. These plant extracts also have a wide spectrum of antimicrobial activities that could be used in the pharmaceutical industries and to control diseases.

\section{Introduction}

Medicinal plants represent an important part of disease remedy in economically weak regions of the world, such as Africa [1, 2]. The South Mediterranean region, including Egypt, is a rich source of medicinal plants that have several uses as alternative medicine across history $[3,4]$. Some of these medicinal plants, such as mint [5-7] and basil $[8,9]$, have been thoroughly investigated. However, many medicinal plants, including Asparagus aethiopicus L. and Citrullus colocynthis L., have not been well studied, especially their phenolic profile and bioactivity.

The genus Asparagus, belonging to the family Liliaceae, contains about 300 species that are widely used as complementary and alternative medicines for treating dysuria, diabetes, epilepsy, night blindness, tumors, and dysentery. They are also used for enhancing appetite and increasing milk secretion in women $[10,11]$. The species $A$. aethiopicus is common across Egypt, and few studies have investigated this species. A study on plants of the South Delta region 
indicated that the leaves of $A$. aethiopicus contain flavonoids and have moderate antioxidant activities [12]. Furthermore, other species of Asparagus have revealed great diversity in their chemical composition. Aberoumand [13] identified fatty acids in the wild Asparagus officinalis from Iran.

Citrullus colocynthis (L.) Schrad, commonly known as bitter apple, belongs to the family Cucurbitaceae and grows naturally in the Egyptian desert. The plant is traditionally used for treating cancer, leukemia, rheumatism, and amenorrhea and also used as an insect repellant $[14,15]$. Gurudeeban et al. [16] reported several traditional uses of the Indian $C$. colocynthis, including its use as antidiabetic, antipyretic, antiinflammatory, antibacterial, and antifungal agents. However, the information available on the Egyptian ecotype of Citrullus colocynthis is scarce in relation to its phenolic composition and bioactivities.

Cymbopogon citratus (Poaceae), commonly known as lemon grass, a native of Southeast Asia, is widely grown in Africa as a medicinal herb [17]. The plant is traditionally used in folk medicine as an anti-inflammatory agent and also used as an insect repellent. A recent investigation indicated the presence of polyphenolic flavonoids, including luteolin and apigenin, with anti-inflammatory activity in the leaves of $C$. citratus [18].

The genus Gasteria, a native of South Africa, contains 23 species. One of the species G. pillansii (L.) Haw, a succulent, is widely cultivated as an ornamental plant in Egypt [19]. Few studies have been conducted on the genus revealing the presence of dihydroanthracenones in G. bicolor [20].

Kalanchoe delagoensis L. (Crassulaceae), a succulent plant, native of Madagascar, is known to contain bufadienolide cardiac glycosides that are toxic [21]. However, thus far, studies have not been conducted to characterize the phenolic profile of this plant.

Brassica juncea (Brassicaceae) is traditionally used as a stimulant, a rubefacient, an emetic, and a diuretic, and it is consumed as food as well [22]. Few studies have indicated that B. juncea contain some phenols [23].

Curcuma longa (Zingiberaceae), commonly known as turmeric, is considered a medicinal plant and is also used as a spice. The roots (rhizomes) are used in traditional Indian and Chinese medicines to treat wounds, acne, flu, and urinary tract and liver diseases [24]. The roots contain phenols, such as diferuloylmethane (curcumin), that have antioxidant and anticancer properties $[25,26]$.

Another common medicinal plant in Egypt is Senna alexandrina L. (Fabaceae), which is distributed around the Nile River. Traditionally, the plant is used for treating stomach pain and constipation, because of its laxative effects [27, 28]. The pods (fruits) have a high percent of glycosides, including the sennosides A, B, C, and D, as well as anthraquinones [29, 30]. The phenolic compounds are the major phytochemicals that are universally present in plants (estimated to be 10,000 compounds) and are responsible for the bioactivity of the plant extracts [31, 32]. The search for natural products in plants is strongly associated with the presence of phenolic compounds, since they have antioxidant and antimicrobial activities [33-35]. The phenolic profile and bioactivities of the traditional medicinal plants in northern Egypt have not been fully explored. In the present study, we aimed to investigate the phenolic qualitative and quantitative profiles of the selected medicinal plants that are used in complementary and alternative medicines by the local people. Furthermore, the antioxidant activity of the extracts was evaluated by $2,2^{\prime}$ diphenylpicrylhydrazyl (DPPH) and $\beta$-carotene-linoleic acid assays. The antibacterial and antifungal activities of each plant were also evaluated to identify and elucidate the bioactivity of the identified main phenolic compounds.

\section{Material and Methods}

2.1. Plant Material. The leaves, fruits, and tubers of $A$. aethiopicus L. (A. sprengeri Regel) and leaves of both $G$. pillansii L. Haw and $K$. delagoensis $\mathrm{L}$. were obtained from the Department of Floriculture and Ornamental Horticulture Nursery in El-Shatby, Alexandria. The fruit coat and flesh with seeds of C. colocynthis L., leaves of C. citratus (DC). Stapf, and pods of $S$. alexandrina Mill were obtained from commercial farms in Alexandria Governorate in northern Egypt. Further, the seeds of $B$. juncea L. and roots of C. longa L. were procured from a local herbalist. All the plants were identified by Dr. H. Elansary and vouchered at the Faculty of Agriculture, Alexandria, in June 2017.

2.2. Bioactivity Assays. To determine the bioactivity of the samples, the total dry weight was determined by drying the cleaned plant parts $(0.25 \mathrm{mg})$ in an oven at $35^{\circ} \mathrm{C}$ to reach a constant weight and then weighed. The samples were then ground and dissolved in $3 \mathrm{~mL}$ methanol (99\%) in dark condition, for $1 \mathrm{~h}$, at room temperature. The extracts were centrifuged at $10,000 \mathrm{rpm}(7000 \times \mathrm{g})$ for $5 \mathrm{~min}$ and the supernatant $(\sim 2.7 \mathrm{~mL})$ was stored at $-80^{\circ} \mathrm{C}$. All the chemicals used were of analytical/HPLC grade bought from SigmaAldrich (Cairo, Egypt). The fungal and bacterial strains were procured from the Departments of Plant Pathology and Floriculture and Ornamental Horticulture, Faculty of Agriculture, Alexandria, Egypt.

2.3. HPLC-DAD Analyses. The plant materials that were dried by lyophilization (Labconco, USA) were powdered using a mortar. The plant samples of $0.2 \mathrm{~g}$ each were extracted following the procedure described by Szopa et al. [36]. The methanolic extracts were subjected to chromatographic analyses by a modified validated HPLC method [37-39]. Quantification was carried out by comparing the UV-DAD spectra and $t_{r}$ values with that of the commercially available standards of the following groups of metabolites: free phenolic acids (3,4-dihydroxyphenylacetic, caffeic, chlorogenic, $o$-coumaric, $m$-coumaric, $p$-coumaric, ferulic, gallic, gentisic, hydrocaffeic, $p$-hydroxybenzoic, isoferulic, neochlorogenic, protocatechuic, rosmarinic, salicylic, sinapic, syringic, and vanillic acids; and precursors of phenolic acids: cinnamic and benzoic acids), flavonoids (aglycones: kaempferol, luteolin, myricetin, quercetin, and rhamnetin; glycosides: apigetrin, cynaroside, hyperoside, isoquercetin, quercitrin, robinin, rutin, trifolin, and vitexin), coumarins (bergapten, esculin, 6-hydroxy-4-methylcoumarin, imperatorin, isopimpinellin, 
marmesin, psoralen, umbelliferone, and xanthotoxin), catechins (epicatechin, epicatechin gallate, epigallocatechin, and epigallocatechin gallate), and phenolic compound biosynthetic precursors (phenylalanine and tyrosine) (the compounds were supplied by Sigma-Aldrich, Germany). An HPLC-DAD (Merck-Hitachi) and a Purospher ${ }^{\circledR}$ RP-18e analytical column $(4 \times 250 \mathrm{~mm}, 5 \mathrm{~mL}$; Merck $)$ were used for the analyses. The gradient program used included the flow rate of $1 \mathrm{~mL} / \mathrm{min}$, injection volume of $10 \mu \mathrm{L}$, and detection wavelength of $254 \mathrm{~nm}$ [36, 40, 41]. The representative chromatograms have been provided as Supplementary Figures 1 and 2.

2.4. Antioxidant Activity. The antioxidant activities of all the samples were determined by DPPH and $\beta$-carotene-linoleic acid assays [9]. In the DPPH method, the absorbance was measured at $517 \mathrm{~nm}$, following $30 \mathrm{~min}$ of treatment. In the $\beta$ carotene-linoleic acid assay, the absorbance was measured at $470 \mathrm{~nm}$. The sample concentration required to scavenge $50 \%$ of the $\mathrm{DPPH} / \beta$-carotene-linoleic acid $\left(\mathrm{IC}_{50}\right.$ in $\left.\mu \mathrm{g} / \mathrm{mL}\right)$ was determined by plotting the inhibition percent against extract concentration. Butylated hydroxytoluene (BHT) was used as a positive control. The antioxidant activity of each sample was compared with that of the BHT and blank. Experiments were repeated twice in triplicate.

2.5. Antibacterial Activity. The antibacterial activity of plant extracts was screened against Gram-positive and Gramnegative bacteria, including Listeria monocytogenes (clinical isolate), Staphylococcus aureus (ATCC 6538), Bacillus cereus (ATCC 14579), Micrococcus flavus (ATCC 10240). Pseudomonas aeruginosa (ATCC 27853), and Escherichia coli (ATCC 35210). The microdilution method was used to determine the minimum inhibitory concentration (MIC) and minimum bactericidal concentration (MBC) of the plant extracts [42]. The 96-well microtiter plates were used, and each well of the plate contained known concentration of plant extracts $+100 \mu \mathrm{L}$ tryptic soy broth containing bacterial inoculum (1.0 $\times 10^{4} \mathrm{CFU}$ per well). These plates were incubated at $37^{\circ} \mathrm{C}$ for $24 \mathrm{~h}$ in a rotary shaker and the MICs and MBCs were determined after the incubation period. The lowest concentration of plant extract that exhibited no visible growth (observed under a binocular microscope) was defined as the MIC. The $\mathrm{MBC}$ was determined using serial subculturing of the $2 \mu \mathrm{L}$ plant extracts into microtiter plates containing $100 \mu \mathrm{L}$ of TSB in each well. The microtiter plates were incubated at $37^{\circ} \mathrm{C}$ for $24 \mathrm{~h}$. The MBC was defined as the lowest concentration that caused no visible growth which indicated killing of $99.5 \%$ of the inoculum. The optical density was determined at $655 \mathrm{~nm}$ and all the experiments were performed twice in triplicate. Positive (streptomycin, $0.01-10 \mathrm{mg} / \mathrm{mL}$ ) and negative (DMSO, 5\%) controls were also used.

2.6. Antifungal Activity. Several fungi, including Aspergillus flavus (ATCC 9643), A. ochraceus (ATCC 12066), A. niger (ATCC 6275), Penicillium ochrochloron (ATCC 48663), $P$. funiculosum (ATCC 56755), and Candida albicans (ATCC 12066), were used to test the antifungal activity of leaf extracts using the microdilution method [42]. Known concentrations of each leaf extract $(2 \mu \mathrm{L})$ were added to microtiter plates (with a capacity of 96 wells) with each well containing broth Malt medium mixed with each fugal inoculum (spore suspension concentration of $1.0 \times 10^{5}$ ). The microtiter plates were incubated at $28^{\circ} \mathrm{C}$ for $72 \mathrm{~h}$ in a rotary shaker. The minimum inhibitory concentrations (MICs) were calculated as the lowest concentration that inhibited fungal growth at the binocular microscopic level. The minimum fungicidal concentrations (MFCs) were calculated using a serial subcultivations of the leaf extracts $(2 \mu \mathrm{L})$ added to microtiter plates that contained $100 \mu \mathrm{L}$ of broth and inoculums and then incubated at $28^{\circ} \mathrm{C}$ for $72 \mathrm{~h}$. The MFC was defined as the minimum concentration that caused no visible growth which indicated the killing of $99.5 \%$ of the original inoculum. The ketoconazole (KTZ) $(1-3500 \mu \mathrm{g} / \mathrm{mL})$ was used as a positive control. All experiments were repeated twice in triplicate.

2.7. Statistical Analyses. Statistical analysis was performed using SPSS version 22.0, and the results were analyzed by least significance difference (LSD) in the ANOVA.

\section{Results}

\subsection{Targeted Profiling of Biologically Active Metabolites}

3.1.1. Asparagus aethiopicus. The HPLC-DAD analysis of fruit, leaf, and tuber extracts of $A$. aethiopicus revealed the differences in the chemical composition between them (Table 1). In the fruit extracts, three phenolic acids, chlorogenic, gallic, and syringic acids, and four flavonoids, isoquercetin, quercetin, quercitrin, and robinin, were confirmed. The predominant phenolic acid was gallic acid (12.20 mg per $100 \mathrm{~g}$ DW), while robinin (kaempferol 3-O-robinoside-7O-rhamnoside) (40.01 mg per $100 \mathrm{~g}$ DW) and quercitrin (quercetin 3-rhamnoside) (37.08 $\mathrm{mg}$ per $100 \mathrm{~g} \mathrm{DW}$ ) were the predominant flavonoids.

In the leaf extracts, four phenolic acids were detected, including caffeic, chlorogenic, gallic, and vanillic acids, with chlorogenic acid (31.72 mg per $100 \mathrm{~g}$ DW) being the most abundant. In the leaf extract relatively high amounts of robinin (1356.90 mg per $100 \mathrm{~g} \mathrm{DW})$, rutin (176.33 mg per $100 \mathrm{~g}$ $\mathrm{DW}$ ), and apigenin (59.59 mg per $100 \mathrm{~g} \mathrm{DW}$ ) were confirmed, as well.

The phenolic profile of tuber extract was relatively poor and revealed four phenolic acids, of which three were similar to those of the leaf extracts (caffeic, chlorogenic, and gallic acids), in addition to protocatechuic acid. Relatively high amounts of caffeic acid (62.18 mg per $100 \mathrm{~g} \mathrm{DW}$ ) and gallic acid (20.33 mg per $100 \mathrm{~g}$ DW) were observed.

3.1.2. Citrullus colocynthis. The extracts of C. colocynthis fruit parts (fruit coat, fruit flesh, and seeds) exhibited similarity in their phenolic profiles (Table 2). Five similar phenolic acids were quantified, including caffeic, $p$-coumaric, ferulic, $p$-hydroxybenzoic, and hydroxycaffeic acids. The hydroxycaffeic acid was the predominant compound $(277.45,117.46$, and $97.25 \mathrm{mg}$ per $100 \mathrm{~g} \mathrm{DW}$ in the fruit coat, fruit flesh, and seed extracts, resp.). Further, the fruit coat and seed extracts contained relatively high amounts of 3,4-dihydroxyphenylacetic 
TABLE 1: Chemical composition of Asparagus aethiopicus and Citrullus colocynthis economic plant parts.

\begin{tabular}{|c|c|c|}
\hline Plant part & Chemical compound & 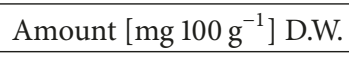 \\
\hline \multirow{7}{*}{ Asparagus aethiopicus (Fruit) } & Chlorogenic acid & $5.21 \pm 0.36$ \\
\hline & Gallic acid & $12.20 \pm 0.06$ \\
\hline & Syringic acid & $2.68 \pm 0.92$ \\
\hline & Quercetin & $12.61 \pm 0.00$ \\
\hline & Quercitrin & $37.08 \pm 0.04$ \\
\hline & Isoquercetin & $7.44 \pm 0.04$ \\
\hline & Robinin & $40.01 \pm 0.06$ \\
\hline \multirow{4}{*}{ A. aethiopicus (tubers) } & Chlorogenic acid & $3.17 \pm 0.76$ \\
\hline & Gallic acid & $20.33 \pm 0.15$ \\
\hline & Caffeic acid & $62.18 \pm 1.03$ \\
\hline & Protocatechuic acid & $8.01 \pm 0.01$ \\
\hline \multirow{7}{*}{ A. aethiopicus (leaves) } & Chlorogenic acid & $31.72 \pm 4.24$ \\
\hline & Gallic acid & $10.39 \pm 2.17$ \\
\hline & Caffeic acid & $11.15 \pm 2.97$ \\
\hline & Vanillic acid & $5.98 \pm 0.66$ \\
\hline & Robinin & $1356.90 \pm 2.18$ \\
\hline & Apigenin & $59.59 \pm 6.11$ \\
\hline & Rutin & $176.33 \pm 0.47$ \\
\hline \multirow{9}{*}{ Citrullus colocynthis (fruit coat) } & Ferulic acid & $2.02 \pm 0.09$ \\
\hline & 3,4-Dihydroxyphenylacetic acid & $221.46 \pm 3.13$ \\
\hline & p-Hydroxybenzoic acid & $2.26 \pm 0.16$ \\
\hline & Hydroxycaffeic acid & $277.45 \pm 15.66$ \\
\hline & Caffeic acid & $4.31 \pm 0.95$ \\
\hline & p-Coumaric acid & $2.80 \pm 0.01$ \\
\hline & 6-Hydroxy-4-methylcoumarin & $58.86 \pm 0.23$ \\
\hline & Syringic acid & $0.22 \pm 0.01$ \\
\hline & Phenylalanine & $747.83 \pm 4.99$ \\
\hline \multirow{5}{*}{ C. colocynthis (fruit flesh) } & Ferulic acid & $3.61 \pm 0.06$ \\
\hline & p-Hydroxybenzoic acid & $5.51 \pm 0.24$ \\
\hline & Hydroxycaffeic acid & $117.46 \pm 17.16$ \\
\hline & Caffeic acid & $13.36 \pm 2.88$ \\
\hline & p-Coumaric acid & $14.47 \pm 2.39$ \\
\hline \multirow{9}{*}{ C. colocynthis (Seeds) } & Ferulic acid & $5.76 \pm 0.68$ \\
\hline & 3,4-Dihydroxyphenylacetic acid & $47.08 \pm 0.10$ \\
\hline & p-Hydroxybenzoic acid & $12.68 \pm 0.24$ \\
\hline & Hydroxycaffeic acid & $97.25 \pm 0.93$ \\
\hline & Caffeic acid & $4.18 \pm 0.09$ \\
\hline & p-Coumaric acid & $2.83 \pm 0.30$ \\
\hline & Protocatechuic acid & $2.25 \pm 0.01$ \\
\hline & Syringic acid & $0.43 \pm 0.05$ \\
\hline & Phenylalanine & $120.78 \pm 1.47$ \\
\hline
\end{tabular}

acid (221.46 and $47.08 \mathrm{mg}$ per $100 \mathrm{~g}$ DW, resp.) and trace amounts of syringic acid ( 0.22 and $0.43 \mathrm{mg}$ per $100 \mathrm{~g} \mathrm{DW})$. In addition to these, the biosynthetic precursor of phenolic compounds, phenylalanine (747.83 and $120.78 \mathrm{mg}$ per $100 \mathrm{~g}$ DW, resp., in the fruit coat and seed extracts) was detected in considerable amount.
3.1.3. Cymbopogon citratus, Gasteria pillansii, and Kalanchoe delagoensis. The phenolic profiles of the economically important part (leaves) of C. citratus, G. pillansii and K. delagoensis were determined (Table 3 ). The leaf extract of $C$. citratus revealed seven phenolic compounds, including one flavonoid (rutin, $155.52 \mathrm{mg}$ per $100 \mathrm{~g} \mathrm{DW}$ ). The amounts of phenolic 
TABle 2: Chemical composition of Senna alexandrina, Brassica juncea, and Curcuma longa economic plant parts.

\begin{tabular}{|c|c|c|}
\hline Plant part & Chemical compound & 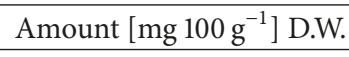 \\
\hline \multirow{18}{*}{ Senna alexandrina (pods or fruits) } & Gallic acid & $15.94 \pm 0.64$ \\
\hline & Gentisic acid & $363.21 \pm 18.64$ \\
\hline & Caffeic acid & $13.34 \pm 0.51$ \\
\hline & Neochlorogenic acid & $65.15 \pm 3.72$ \\
\hline & Protocatechuic acid & $31.52 \pm 1.86$ \\
\hline & Syringic acid & $5.88 \pm 0.23$ \\
\hline & Vanillic acid & $5.06 \pm 0.09$ \\
\hline & Epigallocatechin & $187.50 \pm 0.20$ \\
\hline & Benzoic acid & $369.15 \pm 15.89$ \\
\hline & 6-Hydroxy-4-methylcoumarin & $62.72 \pm 3.70$ \\
\hline & Cynaroside & $73.28 \pm 2.82$ \\
\hline & Kaempferol & $137.74 \pm 0.52$ \\
\hline & Quercetin & $80.06 \pm 3.20$ \\
\hline & Isoquercetin & $195.15 \pm 7.41$ \\
\hline & Luteolin & $22.81 \pm 1.34$ \\
\hline & Rhamnetin & $291.30 \pm 8.73$ \\
\hline & Psoralene & $20.93 \pm 0.27$ \\
\hline & Isorhamnetin & $51.31 \pm 0.99$ \\
\hline \multirow{11}{*}{ Brassica juncea (seeds) } & Chlorogenic acid & $45.03 \pm 4.53$ \\
\hline & Gallic acid & $9.14 \pm 0.06$ \\
\hline & Ferulic acid & $9.49 \pm 0.11$ \\
\hline & Caffeic acid & $5.21 \pm 0.31$ \\
\hline & Neochlorogenic acid & $18.60 \pm 0.02$ \\
\hline & Syringic acid & $2.04 \pm 0.22$ \\
\hline & Vanillic acid & $4.46 \pm 0.08$ \\
\hline & Esculin & $294.90 \pm 0.63$ \\
\hline & Umbelliferone & $277.27 \pm 9.69$ \\
\hline & Sinapic acid & $5.13 \pm 4.32$ \\
\hline & Epigallocatechin & $45.12 \pm 0.03$ \\
\hline \multirow{7}{*}{ Curcuma longa L. (roots) } & Ferulic acid & $15.04 \pm 1.49$ \\
\hline & 3,4-Dihydroxyphenylacetic acid & $33.26 \pm 0.51$ \\
\hline & p-Hydroxybenzoic acid & $2.77 \pm 0.39$ \\
\hline & Hydroxycaffeic acid & $64.40 \pm 1.60$ \\
\hline & p-Coumaric acid & $8.11 \pm 2.62$ \\
\hline & Protocatechuic acid & $2.93 \pm 0.03$ \\
\hline & Syringic acid & $2.22 \pm 0.01$ \\
\hline
\end{tabular}

acids were relatively high, with chlorogenic (49.98 mg per $100 \mathrm{~g} \mathrm{DW})$ and 3,4-dihydroxyphenylacetic acid (60.21 mg per $100 \mathrm{~g}$ DW) being the predominant ones. The biosynthetic precursor of phenolic acids (cinnamic acid, 50.44 mg per $100 \mathrm{~g} \mathrm{DW}$ ) was also found in relatively high amounts.

The phenolic profile of $G$. pillansii leaf extracts contained several phenolic acids such as $p$-coumaric (14.11 mg per $100 \mathrm{~g}$ DW), ferulic (67.62 mg per $100 \mathrm{~g} \mathrm{DW}$ ), and gallic (15.04 mg per $100 \mathrm{~g}$ DW) acids, including their biosynthetic precursor, cinnamic acid (4.80 $\mathrm{mg}$ per $100 \mathrm{~g} \mathrm{DW})$. In the leaf extracts of $G$. pillansii, relatively high amounts of quercitrin $(83.08 \mathrm{mg}$ per $100 \mathrm{~g} \mathrm{DW}$ ) and quercetin (65.81 mg per $100 \mathrm{~g}$ DW) were confirmed, in addition to the other flavonoids, isoquercetin, and rutin.
The leaf extracts of $K$. delagoensis contained relatively high amounts of phenolic acids and flavonoids. Five phenolic acids were detected in significant amounts, including gallic acid (152.21 mg per $100 \mathrm{~g}$ DW) and caffeic acid $(65.28 \mathrm{mg}$ per $100 \mathrm{~g} \mathrm{DW})$. High amounts of the flavonoids such as trifolin (kaempferol 3-galactoside) (873.63 mg per $100 \mathrm{~g}$ DW), kaempferol (207.41 mg per $100 \mathrm{~g} \mathrm{DW}$ ), isoquercetin (120.58 mg per $100 \mathrm{~g} \mathrm{DW})$, and quercitrin (89.86 mg per $100 \mathrm{~g}$ DW) were detected.

3.1.4. Brassica juncea. The seed extracts of $B$. juncea revealed the presence of phenolic acids, coumarins, and epigallocatechin (Table 4). The predominant phenolic acids included chlorogenic acid (45.03 mg per $100 \mathrm{~g} \mathrm{DW}$ ) and its isomer, 
TABle 3: Chemical composition of Cymbopogon citratus, Gasteria pillansii, and Kalanchoe delagoensis economic plant parts.

\begin{tabular}{|c|c|c|}
\hline Plant part & Chemical compound & Amount $\left[\mathrm{mg}^{\left.100 \mathrm{~g}^{-1}\right]}\right.$ D.W. \\
\hline \multirow{7}{*}{ Cymbopogon citratus (leaves) } & Chlorogenic acid & $49.98 \pm 0.62$ \\
\hline & Cinnamic acid & $50.44 \pm 0.03$ \\
\hline & 3,4-Dihydroxyphenylacetic acid & $60.21 \pm 0.60$ \\
\hline & Caffeic acid & $8.74 \pm 0.02$ \\
\hline & Protocatechuic acid & $4.36 \pm 0.02$ \\
\hline & Vanillic acid & $2.95 \pm 0.03$ \\
\hline & Rutin & $155.52 \pm 0.32$ \\
\hline \multirow{9}{*}{ Gasteria pillansii/G. maculata (leaves) } & Cinnamic acid & $4.80 \pm 1.23$ \\
\hline & Ferulic acid & $67.62 \pm 2.25$ \\
\hline & Gallic acid & $15.04 \pm 0.01$ \\
\hline & Ferulic acid & $27.15 \pm 0.05$ \\
\hline & p-Coumaric acid & $14.11 \pm 5.54$ \\
\hline & Quercetin & $65.81 \pm 4.50$ \\
\hline & Isoquercetin & $8.04 \pm 0.89$ \\
\hline & Quercitrin & $83.08 \pm 11.05$ \\
\hline & Rutin & $41.83 \pm 5.04$ \\
\hline \multirow{12}{*}{ Kalanchoe delagoensis L. or Bryophyllum delagoense L. (leaves) } & Ferulic acid & $25.92 \pm 0.12$ \\
\hline & Gallic acid & $152.21 \pm 0.45$ \\
\hline & Caffeic acid & $65.28 \pm 0.71$ \\
\hline & Protocatechuic acid & $32.38 \pm 0.11$ \\
\hline & Syringic acid & $11.90 \pm 0.62$ \\
\hline & Trifoline & $873.63 \pm 2.82$ \\
\hline & Kaempferol-7 o-rhamnoside & $47.65 \pm 0.42$ \\
\hline & Kaempferol & $207.41 \pm 0.94$ \\
\hline & Quercetin & $89.86 \pm 1.49$ \\
\hline & Isoquercetin & $120.58 \pm 1.01$ \\
\hline & Robinin & $125.69 \pm 1.98$ \\
\hline & Quercitrin & $155.65 \pm 0.88$ \\
\hline
\end{tabular}

TABLE 4: DPPH and $\beta$-carotene-linoleic acid assay of A. aethiopicus, C. colocynthis, S. alexandrina, B. juncea, C. longa, C. citratus, G. pillansii, and $K$. delagoensis methanolic extracts. Values are expressed as mean of triplicate determinations \pm sd.

\begin{tabular}{lcc}
\hline & $\begin{array}{c}\mathrm{DPPH} \text { free radical } \\
\text { scavenging activity }_{\left(\mathrm{I}_{50}, \mu \mathrm{g} \mathrm{mL}\right)}\end{array}$ & $\begin{array}{c}\beta \text {-Carotene- } \\
\text { linoleic acid assay } \\
\left(\mathrm{IC}_{50}, \mu \mathrm{g} \mathrm{mL}^{-1}\right)\end{array}$ \\
\hline Asparagus aethiopicus (leaves) & $3.1 \pm 0.1$ & $2.7 \pm 0.1$ \\
Asparagus aethiopicus (fruit) & $8.4 \pm 0.1$ & $9.9 \pm 0.1$ \\
Asparagus aethiopicus (tubers) & $8.1 \pm 0.1$ & $9.5 \pm 0.1$ \\
Citrullus colocynthis (fruit coat) & $2.4 \pm 0.1$ & $2.3 \pm 0.1$ \\
Citrullus colocynthis (fruit flesh) & $6.5 \pm 0.2$ & $7.8 \pm 0.3$ \\
Citrullus colocynthis seeds & $7.8 \pm 0.1$ & $8.9 \pm 0.3$ \\
Senna alexandrina (pods or fruit) & $2.6 \pm 0.1$ & $2.4 \pm 0.1$ \\
Brassica juncea (seeds) & $5.4 \pm 0.1$ & $6.2 \pm 0.1$ \\
Curcuma longa L. (roots) & $7.3 \pm 0.3$ & $8.2 \pm 0.1$ \\
Cymbopogon citratus (leaves) & $8.3 \pm 0.3$ & $9.4 \pm 0.3$ \\
Gasteria pillansii (leaves) & $5.4 \pm 0.1$ & $6.5 \pm 0.1$ \\
Kalanchoe delagoense L. (leaves) & $4.1 \pm 0.1$ & $4.9 \pm 0.1$ \\
BHT & $2.9 \pm 0.2$ & $2.6 \pm 0.1$ \\
\hline
\end{tabular}


neochlorogenic acid (18.60 mg per $100 \mathrm{~g} \mathrm{DW})$. Other phenolic acids (caffeic, ferulic, gallic, sinapic, syringic, and vanillic acids) were also quantified; however, they were in relatively low amounts $(<10 \mathrm{mg}$ per $100 \mathrm{~g} \mathrm{DW})$. In the seed extracts, two coumarins, esculin (294.90 mg per $100 \mathrm{~g}$ DW) and umbelliferone (277.27 mg per $100 \mathrm{~g} \mathrm{DW}$ ), were confirmed.

3.1.5. Curcuma longa. The chromatographic analysis of the $C$. longa root extracts revealed the presence of seven phenolic aids, including $p$-coumaric, 3,4-dihydroxyphenylacetic, ferulic, $p$-hydroxybenzoic, hydroxycaffeic, protocatechuic, and syringic acids. The predominant compounds were hydroxycaffeic acid (64.40 mg per $100 \mathrm{~g}$ DW), 3,4-dihydroxyphenylacetic acid (33.26 mg per $100 \mathrm{~g} \mathrm{DW})$, and ferulic acid (15.04 mg per $100 \mathrm{~g} \mathrm{DW})$.

3.1.6. Senna alexandrina. The pod extract of S. alexandrina contained three groups of secondary metabolites, including phenolic acids, flavonoids, and coumarins (Table 6). The precursor of the phenolic acids, benzoic acid, was quantified in relatively high amount (369.15 mg per $100 \mathrm{~g} \mathrm{DW})$. Also, seven phenolic acids (caffeic, gallic, gentisic, neochlorogenic, protocatechuic, syringic, and vanillic acids) were detected. High amounts of gentisic acid (363.21 mg per $100 \mathrm{~g} \mathrm{DW})$, neochlorogenic acid ( $65.15 \mathrm{mg}$ per $100 \mathrm{~g} \mathrm{DW})$, and protocatechuic acid (31.52 mg $100 \mathrm{~g} \mathrm{DW})$ were detected.

Furthermore, seven flavonoids (cynaroside, isoquercetin, isorhamnetin, kaempferol, luteolin, quercetin, and rhamnetin) were detected in relatively high amounts ranging from 22.81 to $291.30 \mathrm{mg}$ per $100 \mathrm{~g}$ DW. The predominant compounds were rhamnetin $(291.30 \mathrm{mg}$ per $100 \mathrm{~g}$ DW), isoquercetin (195.15 mg per $100 \mathrm{~g} \mathrm{DW}$ ), and kaempferol (137.74 mg per $100 \mathrm{~g} \mathrm{DW}$ ). In the S. alexandrina pod extracts, two coumarins, 6-hydroxy-4-methylcoumarin (62.72 mg per $100 \mathrm{~g} \mathrm{DW}$ ) and psoralene (20.93 mg per $100 \mathrm{~g} \mathrm{DW}$ ), were also detected.

3.2. Antioxidant Activities. Methanolic extracts of the leaves were subjected to DPPH and $\beta$-carotene-linoleic acid assays, and the results are presented in Table 4. The antioxidant activities expressed as $\mathrm{IC}_{50}$ ranged from 2.4 to $8.4 \mu \mathrm{g} / \mathrm{mL}$ and 2.3 to $9.9 \mu \mathrm{g} / \mathrm{mL}$ in the DPPH and $\beta$-carotene-linoleic acid assays, respectively.

Relatively high antioxidant activities (low $\mathrm{IC}_{50}, \mu \mathrm{g} / \mathrm{mL}$ ) was exhibited by C. colocynthis fruit coat $(\mathrm{DPPH}=2.4 ; \beta$ carotene $=2.3)$, S. alexandrina pods $(\mathrm{DPPH}=2.6 ; \beta$-carotene $=2.4)$, and $A$. aethiopicus leaves $(\mathrm{DPPH}=3.1 ; \beta$-carotene $=$ 2.7). They showed higher antioxidant activities than that of the BHT standard. Other plant samples of $K$. delagoensis, $G$. pillansii, and B. juncea revealed moderate antioxidant activities. Relatively low antioxidant activities were observed in A. aethiopicus fruits and tubers, C. colocynthis fruit flesh and seeds, C. longa roots, and C. citratus leaves. Both the assays followed a similar pattern in their values for the antioxidant activities.

3.3. Antibacterial Activities. The plant parts showed great variation in the antibacterial activities, expressed as MIC and MBC, of their methanolic extracts (Table 5). The MIC and
MBC ranged from 0.02 to $0.43 \mathrm{mg} / \mathrm{mL}$ and 0.4 to $0.73 \mathrm{mg} / \mathrm{mL}$, respectively. The pods of $S$. alexandrina, $C$. colocynthis fruit coat, and $A$. aethiopicus leaves revealed relatively high antibacterial activities, with relatively low MIC and MBC compared to streptomycin. The fruit flesh and seeds of $C$. colocynthis showed moderate to high antibacterial activities against bacteria, such as P. aeruginosa, E. coli, M. flavus, and $S$. aureus. The seeds of $B$. juncea and roots of $C$. longa revealed high to moderate antibacterial activities when compared with other plants. The tubers of A. aethiopicus exhibited relatively low antibacterial activity against most organisms.

3.4. Antifungal Activities. The antifungal activities of methanolic extracts were expressed as MIC and MFC (Table 6). The MIC and MFC values ranged from 0.08 to $0.33 \mathrm{mg} / \mathrm{mL}$ and 0.16 to $0.75 \mathrm{mg} / \mathrm{mL}$, respectively. The fruit coat of C. colocynthis, pods of S. alexandrina, and leaves of A. aethiopicus showed relatively high antifungal activities in general with low MIC and MBC values compared to the standard reagent. The other plant extracts, such as $C$. colocynthis fruit flesh and seeds, $B$. juncea seeds, and $C$. longa roots, exhibited moderate antifungal activities.

\section{Discussion}

The extracts of A. aethiopicus (leaves, fruits, and tubers), $G$. pillansii (leaves), S. alexandrina (pods), C. colocynthis (fruit coat and flesh and seeds), K. delagoensis (leaves), C. citratus (leaves), B. juncea (seeds), and C. longa (roots) revealed significant variations in their phenol profile (Tables 1-6). The major compound found in the leaves of A. aethiopicus was the glucoside flavonoid, robinin $(1356.90 \mathrm{mg}$ per $100 \mathrm{~g} \mathrm{DW})$. Its concentration was significantly higher than that of all other compounds detected in the investigated samples. The sources of robinin, in nature, are limited; few investigations have detected this flavonoid in some plants, such as Pueraria lobata [43]. However, the present study revealed a rich and new source of robinin, the leaves of $A$. aethiopicus. Previous investigations on $A$. aethiopicus have isolated other flavonoids, including apigenin, apigenin-7$O$-glucoside, dihydroquercetin, and naringenin, and they also reported moderate antioxidant activity of the alcoholic extract [12]. However, in the present study, 12 phenolic compounds were isolated from the leaves, fruits, and tubers, in addition to apigenin in relatively low amount in the leaves.

In C. colocynthis, the fruit coat had higher phenylalanine content when compared with other extracts, including the seed and fruit flesh of colocynthis. A previous study has reported the presence of phenylalanine in the seeds of the Indian C. colocynthis [16]. However, the present study was the first to report six times higher phenylalanine content in the fruit coat of $C$. colocynthis than that of the seeds in the Egyptian ecotype. Further, the fruit coat contained other major compounds, such as 3,4-dihydroxyphenylacetic acid and hydroxycaffeic acid. The pods of $S$. alexandrina contained high amounts of gentisic acid, benzoic acid, rhamnetin, isoquercetin, and kaempferol, and the presence of these compounds have not been reported. However, Franz [27] reported the presence of other glycosides, belonging to 


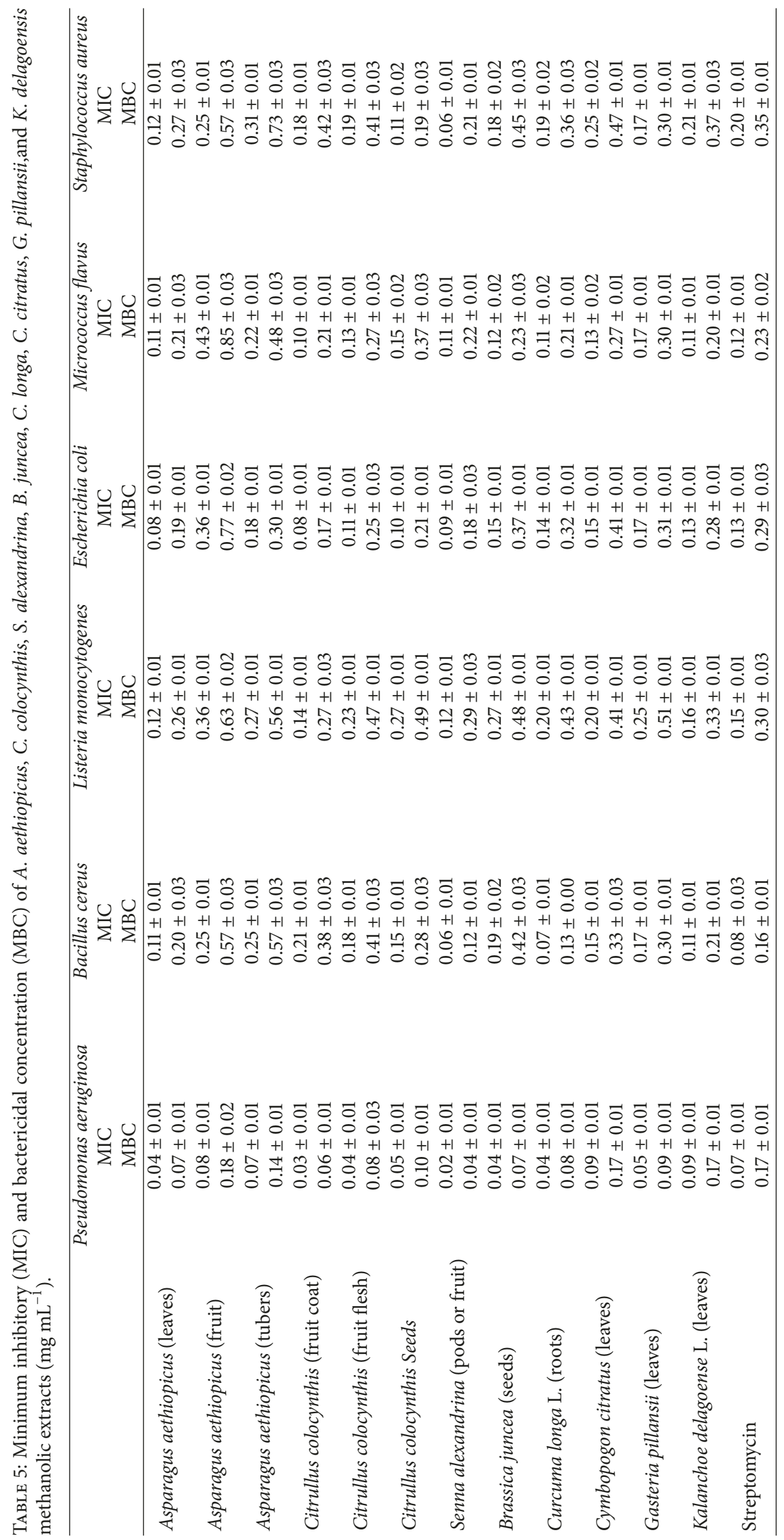




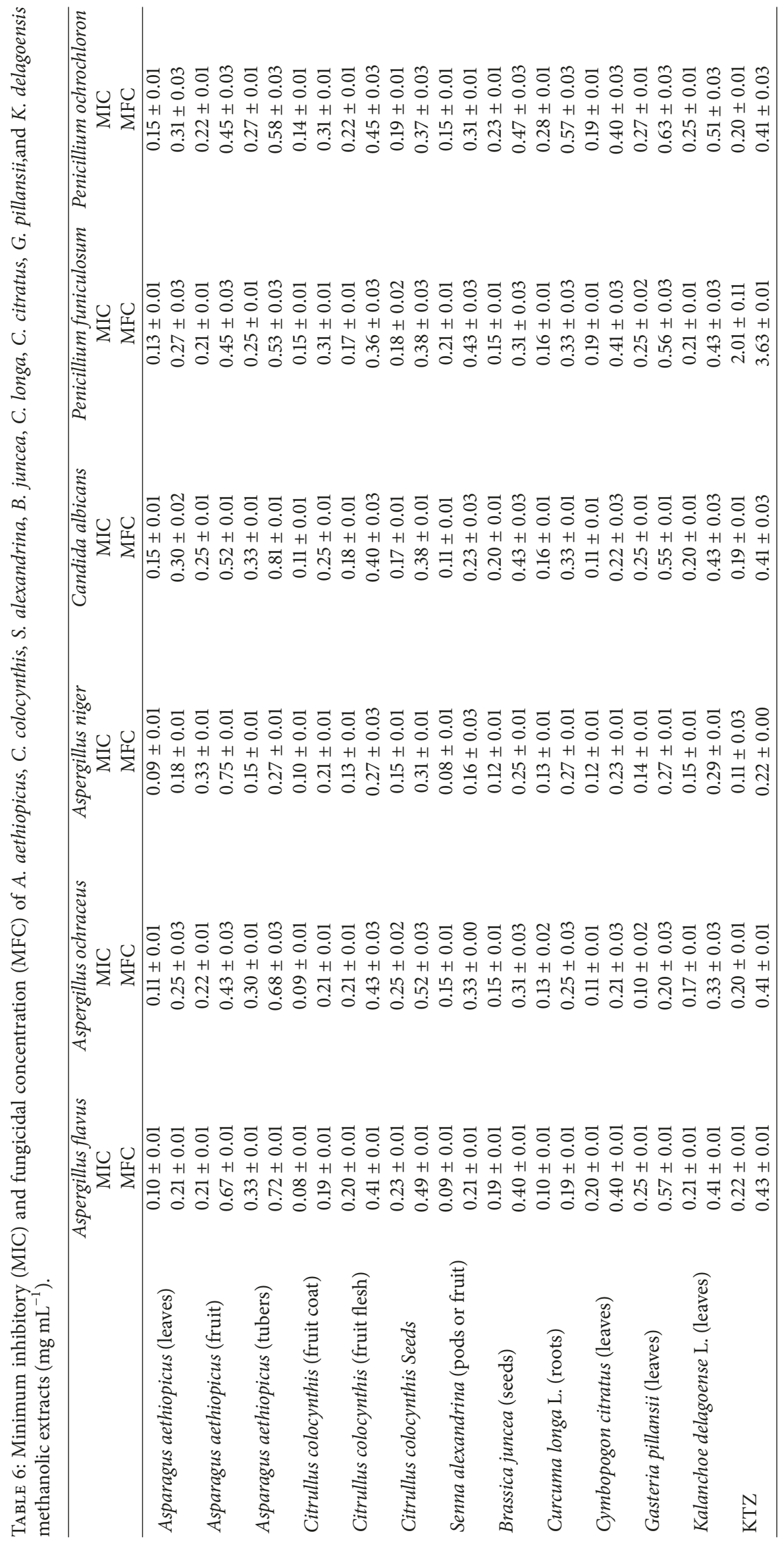


the anthraquinone family, in S. alexandrina. In the present study, $B$. juncea seeds contained high amounts of esculin, umbelliferone, epigallocatechin, and chlorogenic acid. A previous study conducted on the extracts of Indian $B$. juncea confirmed the presence of sinigrin, quercetin, vanillin, and catechin [23].

The presence of phenolic compounds, such as hydroxycaffeic acid in C. longa roots; rutin, 3,4-dihydroxyphenylacetic acid, chlorogenic acid, and cinnamic acid in $C$. citratus; quercitrin, ferulic acid, and quercetin in G. pillansii; trifoline, kaempferol, quercitrin, gallic acid, and isoquercetin in $K$. delagoensis have not been reported before this study. However, a study on $C$. citratus reported the presence of specific flavonoids with anti-inflammatory activity, such as carlinoside, isoorientin, cynaroside, and luteolin [18]. Furthermore, 3,4-dihydroxyphenylacetic acid is considered as a metabolite of curcumin and has been reported in C. longa [26].

High antioxidant activity is usually associated with the phenols in the plants, especially the more abundant phenols $[9,44,45]$. Phenols are the secondary metabolites of plants with obvious antioxidant activities. Flavonoids, a class of phenols, such as kaempferol, tripholine, astragalin, robinin, and quercetin, have strong antioxidants that limit free radical accumulation and scavenge free radicals [46]. In the present study, relatively high antioxidant activities were found in C. colocynthis fruit coat, $S$. alexandrina pods, and $A$. aethiopicus, and the major compounds detected in these plant extracts were phenylalanine, benzoic acid, and robinin, respectively. Recent studies indicated that phenylalanine and benzoic acid might be strong antioxidants $[47,48]$. Further, the fruit coat of $C$. colocynthis, with relatively high 3,4dihydroxyphenylacetic content in the present study, has been associated with strong antioxidant activity [49]. Lau et al. [43] reported high antioxidant activity of Pueraria lobata containing high amounts of robinin, which is analogous to the findings of the present study. The high antioxidant activity exhibited by $A$. aethiopicus might be attributed to the high robinin content. The leaves of $A$. aethiopicus contained other phenolic compounds, such as rutin and chlorogenic acid, and these compounds have been known to have strong antioxidant activities [50].

Previous investigations [51, 52] have indicated that the phenols and flavonoids present in the plants may have an influence on the microorganism growth. Generalić et al. [51] reported that leaf extracts of Salvia officinalis L. contained high amounts of phenols and flavonoids exhibiting high antibacterial activity, especially against $E$. coli, S. aureus, and $B$. cereus. In the present study, relatively high antibacterial activities were discovered in the extracts of $S$. alexandrina pods, C. colocynthis fruit coat, and A. aethiopicus leaves. The phenylalanine in the $C$. colocynthis fruit coat has been reported to have antibacterial activity [53]. Ali et al. [54] reported that the Weinreb amides 3, 4, and 5 of alanine and phenylalanine exhibited good activity against E. coli and Pseudomonas aeruginosa; however, poor results were observed against $S$. aureus and B. subtilis. Further, Gurudeeban et al. [16] reported high antibacterial activity of the methanolic extracts of $C$. colocynthis fruits against bacteria, such as B. subtilis, Streptococcus pyogenes, and Salmonella typhi. Robinin extracted from Robinia pseudoacacia L. has high antibacterial activity $[55,56]$. Benzoic acid and its derivatives have antibacterial activities and might be used as food preservatives [57]. In the present study, the fruit coat of C. colocynthis, pods of $S$. alexandrina, and leaves of $A$. aethiopicus showed relatively high antifungal activities in general, which might be attributed to high amounts of specific phenols in these plants. This is in agreement with the results of previous investigations $[58,59]$. Zhang et al. [60] reported high antifungal activities of Robinia pseudoacacia extracts, and this was attributed to high robinin content. Further, Al-Snafi [61] emphasized the antibacterial and antifungal activities of the seeds of $C$. colocynthis. However, the present study was the first to explore the profile of these important phenols in C. colocynthis fruit parts. Further, Gurudeeban et al. [16] reported strong antifungal activities of C. colocynthis against Aspergillus fumigatus and Mucor sp.

\section{Conclusions}

The plants studied revealed great diversity in their phenolic profile and also their antioxidant, antibacterial, and antifungal activities. The major phenols identified were robinin in the leaves and fruits of A. aethiopicus, caffeic acid in A. aethiopicus (tubers), quercitrin in G. pillansii (leaves), benzoic acid in S. alexandrina (pods), phenylalanine in C. colocynthis (fruit coat and seeds), hydroxycaffeic acid in C. colocynthis (fruit flesh), trifoline in $K$. delagoensis (leaves), rutin in C. citratus (leaves), esculin in $B$. juncea (seeds), and hydroxycaffeic acid in $C$. longa (roots). The leaves of $A$. aethiopicus had relatively high amount of the phenolic compound, robinin compared with the other plants studied. Relatively high antioxidant, antibacterial, and antifungal activities were observed in $C$. colocynthis fruit coat, S. alexandrina pods, and A. aethiopicus. The high bioactivity of plant extracts was associated with the presence of phenols, especially the more abundant phenols: phenylalanine, benzoic acid, and robinin, respectively. Further, it could be concluded that the fruit coat of C. colocynthis, pods of S. alexandrina, and parts of $A$. aethiopicus might be excellent sources of natural products that could be used in the pharmaceutical industries and control of diseases.

\section{Conflicts of Interest}

The authors declare that there are no conflicts of interest regarding the publication of this paper.

\section{Acknowledgments}

The study was funded by the Deanship of Scientific Research at King Saud University through Research Group no. RG 1435-011. Further, this study was supported by the Faculty of Agriculture, Alexandria University, Egypt (2017).

\section{Supplementary Materials}

Figure 1: the HPLC-UV chromatogram of methanolic extract from Asparagus aethiopicus leaf: 1, gallic acid; 2, chlorogenic acid; 3 , vanillic acid; 4, caffeic acid; 5, robinin; 6 , rutin; 7 , 
apigenin. Figure 2: the HPLC-UV chromatogram of methanolic extract from Senna alexandrina fruit: 1, gallic acid; 2, neochlorogenic acid; 3 , protocatechuic acid; 4, epigallocatechin; 5, gentisic acid; 6 , vanillic acid; 7 , caffeic acid; 8 , syringic acid; 9, 6-hydroxy-4-methylcoumarin; 10, benzoic acid; 11, cynaroside; 12, isoquercetin; 13, psoralene; 14, quercetin; 15 luteolin; 16, kaempferol; 17, isorhamnetin; 18, rhamnetin. (Supplementary Materials)

\section{References}

[1] K. Hostettmann, A. Marston, K. Ndjoko, and J.-L. Wolfender, "The potential of African plants as a source of drugs," Current Organic Chemistry, vol. 4, no. 10, pp. 973-1010, 2000.

[2] M. Mander, L. Ntulii, N. Diederichsi, and K. Mavundla, "Economics of the traditional medicine trade in South Africa," in South African health review 2007, S. Harrison, R. Bhana, and A. and, Eds., Health Systems Trust, Durban, South Africa, 2007.

[3] M. El-Demerdash, "Medicinal plants of Egypt," in Development of plant-based medicines: conservation, efficacy and safety, $\mathrm{P}$. K. Saxena, Ed., pp. 69-93, Kluwer Academic Publishers, Dordrecht, The Netherlands, 2001.

[4] H. O. Elansary, E. A. Mahmoud, S. Shokralla, and K. Yessoufou, "Diversity of plants, traditional knowledge, and practices in local cosmetics: A case study from Alexandria, Egypt," Economic Botany, vol. 69, no. 2, article no. A005, pp. 114-126, 2015.

[5] A. E. Edris, A. S. Shalaby, H. M. Fadel, and M. A. Abdel-Wahab, "Evaluation of a chemotype of spearmint (Mentha spicata L.) grown in Siwa Oasis, Egypt," European Food Research and Technology, vol. 218, no. 1, pp. 74-78, 2003.

[6] H. O. Elansary and N. A. Ashmawy, "Essential Oils of Mint between Benefits and Hazards," Journal of Essential Oil Bearing Plants, vol. 16, no. 4, pp. 429-438, 2013.

[7] H. O. Elansary and E. A. Mahmoud, "Egyptian herbal tea infusions' antioxidants and their antiproliferative and cytotoxic activities against cancer cells," Natural Product Research (Formerly Natural Product Letters), vol. 29, no. 5, pp. 474-479, 2015.

[8] H. O. Elansary and E. A. Mahmoud, "Basil cultivar identification using chemotyping still favored over genotyping using core barcodes and possible resources of antioxidants," Journal of Essential Oil Research, vol. 27, no. 1, pp. 82-87, 2015.

[9] H. O. Elansary and E. A. Mahmoud, "In vitro antioxidant and antiproliferative activities of six international basil cultivars," Natural Product Research, vol. 29, no. 22, pp. 2149-2154, 2015.

[10] R. D. Gaur, The Flora of the District Garhwal North West Himalaya, 1999.

[11] K. R. Kirtikar and B. D. Basu, Indian Medicinal Plants, B. Singh and M. P. Singh, Eds., New Connaught Place, Dehradun, India, 1984.

[12] R. A. Hassan, W. A. Tawfeek, A. A. Habeeb, M. S. Mohamed, Khaled, and A. Abdelshafeek, "Investigation of some chemical constituents and antioxidant activity of asparagus sperngeri," International Journal of Pharmacy and Pharmaceutical Sciences, vol. 6, no. 11, pp. 46-51, 2014.

[13] A. Aberoumand, "Identification of fatty acids in edible wild plants by gas chromatography," Food Analytical Methods, vol. 2, no. 3, pp. 208-211, 2008.

[14] L. Boulos, Medicinal Plants of North Africa, Reference Publication Inc., Algonac, Mich, USA, 1983.

[15] H. M. Torkey, H. M. Abou-Yousef, A. Azeiz, and H. E. A. Farid, "Insecticidal effect of Cucurbitacin E Glycoside isolated from Citrullus colocynthis against Aphis craccivora," Australian Journal of Basic and Applied Sciences, vol. 3, no. 4, pp. 40604066, 2009.

[16] S. Gurudeeban, K. Satyavani, and T. Ramanathan, "Bitter apple (Citrullus colocynthis): An overview of chemical composition and biomedical potentials," Asian Journal of Plant Sciences, vol. 9, no. 7, pp. 394-401, 2010.

[17] A. Figueirinha, M. T. Cruz, V. Francisco, M. C. Lopes, and M. T. Batista, "Anti-inflammatory activity of cymbopogon citratus leaf infusion in lipopolysaccharide-stimulated dendritic cells: contribution of the polyphenols," Journal of Medicinal Food, vol. 13, no. 3, pp. 681-690, 2010.

[18] G. Costa, J. P. Ferreira, C. Vitorino et al., "Polyphenols from Cymbopogon citratus leaves as topical anti-inflammatory agents," Journal of Ethnopharmacology, vol. 178, pp. 222-228, 2016.

[19] B. H. Daru, J. C. Manning, J. S. Boatwright et al., "Molecular and morphological analysis of subfamily Alooideae (Asphodelaceae) and the inclusion of Chortolirion in Aloe," Taxon, vol. 62, no. 1, pp. 62-76, 2013.

[20] E. Dagne, B.-E. Van Wyk, M. Mueller, and W. Steglich, “Three dihydroanthracenones from Gasteria bicolor," Phytochemistry, vol. 41, no. 3, pp. 795-799, 1996.

[21] R. A. McKenzie, F. P. Franke, and P. J. Dunster, "The toxicity to cattle and bufadienolide content of six Bryophyllum species.," Australian Veterinary Journal, vol. 64, no. 10, pp. 298-301, 1987.

[22] M. Anuradha, D. Pragyandip, P. N. Murthy, H. H. Siddique, and K. Poonam, "A classical review on Rajika (Brassica juncea)," Journal of Botanical Sciences, vol. 1, pp. 18-23, 2012.

[23] H. Parikh and K. Aparna, "Pharmacognosy and phytochemical analysis of brassica juncea seeds," Pharmacognosy Journal, vol. 6, no. 5, pp. 47-54, 2014.

[24] N. Chainani-Wu, "Safety and anti-inflammatory activity of curcumin: a component of tumeric (Curcuma longa)," The Journal of Alternative and Complementary Medicine, vol. 9, no. 1, pp. 161-168, 2003.

[25] R. A. Sharma, A. J. Gescher, and W. P. Steward, "Curcumin: the story so far," European Journal of Cancer, vol. 41, no. 13, pp. 19551968, 2005.

[26] R. K. Maheshwari, A. K. Singh, J. Gaddipati, and R. C. Srimal, "Multiple biological activities of curcumin: a short review," Life Sciences, vol. 78, no. 18, pp. 2081-2087, 2006.

[27] G. Franz, "The senna drug and its chemistry," Pharmacology, vol. 47, no. 1, pp. 2-6, 1993.

[28] P. Monkheang, R. Sudmoon, T. Tanee, K. Noikotr, N. Bletter, and A. Chaveerach, "Species diversity, usages, molecular markers and barcode of medicinal Senna species (Fabaceae, Caesalpinioideae) in Thailand," Journal of Medicinal Plant Research, vol. 5, no. 26, pp. 6173-6181, 2011.

[29] S. Aurapa and G. Wandee, "Determination of anthraquinone glycosides in Cassia fistula leaf extracts for alternative source of laxative drug," vol. 3, pp. 42-45, 2009.

[30] A. M. El-hassan, M. E. Shayoub, M. A. Abdalkreem, H. M. Osman, and K. Khalifa, "Design, formulation, and evaluation of senna effervescent tablets," Journal of Forest Products and Industries, vol. 1, pp. 21-25, 2012.

[31] A.-N. Li, S. Li, Y.-J. Zhang, X.-R. Xu, Y.-M. Chen, and H.-B. $\mathrm{Li}$, "Resources and biological activities of natural polyphenols," Nutrients, vol. 6, no. 12, pp. 6020-6047, 2014. 
[32] N. C. Souza, J. M. De Oliveira, M. Da Silva Morrone et al., "Antioxidant and Anti-Inflammatory Properties of Anacardium occidentale Leaf Extract," Evidence-Based Complementary and Alternative Medicine, vol. 2017, Article ID 2787308, 2017.

[33] F. N. Muanda, J. Bouayed, A. Djilani, C. Yao, R. Soulimani, and A. Dicko, "Chemical composition and, cellular evaluation of the antioxidant activity of Desmodium adscendens leaves," Evidence-Based Complementary and Alternative Medicine, vol. 2011, Article ID 620862, 9 pages, 2011.

[34] J. Fan, M. H. Johnson, M. A. Lila, G. Yousef, and E. G. De Mejia, "Berry and citrus phenolic compounds inhibit dipeptidyl peptidase IV: Implications in diabetes management," EvidenceBased Complementary and Alternative Medicine, vol. 2013, Article ID 479505, 13 pages, 2013.

[35] A. Rodriguez-Garcia, I. T. A. Peixoto, M. J. Verde-Star, S. De La Torre-Zavala, H. Aviles-Arnaut, and A. L. T. G. Ruiz, "In Vitro Antimicrobial and Antiproliferative Activity of Amphipterygium adstringens," Evidence-Based Complementary and Alternative Medicine, vol. 2015, Article ID 175497, 7 pages, 2015.

[36] A. Szopa, A. Kokotkiewicz, M. Bednarz, M. Luczkiewicz, and H. Ekiert, "Studies on the accumulation of phenolic acids and flavonoids in different in vitro culture systems of Schisandra chinensis (Turcz.) Baill. using a DAD-HPLC method," Phytochemistry Letters, vol. 20, pp. 462-469, 2017.

[37] M. Ellnain-Wojtaszek and G. Zgorka, "High-performance liquid chromatography and thin-layer chromatography of phenolic acids from Ginkgo biloba L. leaves collected within vegetative period," Journal of Liquid Chromatography \& Related Technologies, vol. 22, no. 10, pp. 1457-1471, 1999.

[38] A. Szopa and H. Ekiert, "Production of biologically active phenolic acids in Aronia melanocarpa (Michx.) Elliott in vitro cultures cultivated on different variants of the Murashige and Skoog medium," Plant Growth Regulation, vol. 72, no. 1, pp. 5158, 2014.

[39] K. Sułkowska-Ziaja, A. Maślanka, A. Szewczyk, and B. Muszyńska, "Physiologically active compounds in four species of phellinus," Natural Product Communications (NPC), vol. 12, no. 3, pp. 363-366, 2017.

[40] A. Szopa, H. Ekiert, A. Szewczyk, and E. Fugas, "Production of bioactive phenolic acids and furanocoumarins in in vitro cultures of Ruta graveolens L. and Ruta graveolens ssp. divaricata (Tenore) Gams. under different light conditions," Plant Cell, Tissue and Organ Culture, vol. 110, no. 3, pp. 329-336, 2012.

[41] A. Szopa, A. Kokotkiewicz, P. Kubica et al., "Comparative analysis of different groups of phenolic compounds in fruit and leaf extracts of Aronia sp.: A. melanocarpa, A. arbutifolia, and A. xprunifolia and their antioxidant activities," European Food Research and Technology, vol. 243, no. 9, pp. 1645-1657, 2017.

[42] H. O. Elansary, J. Norrie, H. M. Ali, M. Z. M. Salem, E. A. Mahmoud, and K. Yessoufou, "Enhancement of Calibrachoa growth, secondary metabolites and bioactivity using seaweed extracts," BMC Complementary and Alternative Medicine, vol. 16, no. 1, article no. 341, 2016.

[43] C. S. Lau, D. J. Carrier, R. R. Beitle et al., "A glycoside flavonoid in Kudzu (Pueraria lobata)," Applied Biochemistry and Biotechnology, vol. 2005, pp. 121-124, 2005.

[44] D. Yu, W. Pu, D. Li, D. Wang, Q. Liu, and Y. Wang, "Phenolic Compounds and Antioxidant Activity of Different Organs of Potentilla fruticosa L. from Two Main Production Areas of China," Chemistry \& Biodiversity, vol. 13, no. 9, pp. 1140-1148, 2016.
[45] H. O. Elansary and K. Yessoufou, "In vitro antioxidant, antifungal and antibacterial activities of five international Calibrachoa cultivars," Natural Product Research, vol. 30, no. 11, pp. 13391342, 2016.

[46] P. G. Pietta, "Flavonoids as antioxidants," Journal of Natural Products, vol. 63, no. 7, pp. 1035-1042, 2000.

[47] W. Li, L. Feng, Y. Liu et al., "Effects of dietary phenylalanine on growth, digestive and brush border enzyme activities and antioxidant capacity in the hepatopancreas and intestine of young grass carp (Ctenopharyngodon idella)," Aquaculture Nutrition, vol. 21, no. 6, pp. 913-925, 2015.

[48] B. Velika and I. Kron, "Antioxidant properties of benzoic acid derivatives against Superoxide radical," Free Radicals and Antioxidants, vol. 2, no. 4, pp. 62-67, 2012.

[49] V. Raneva, H. Shimasaki, Y. Ishida, N. Ueta, and E. Niki, "Antioxidative activity of 3,4-dihydroxyphenylacetic acid and caffeic acid in rat plasma," Lipids, vol. 36 , no. 10, article no. 821 , pp. 1111-1116, 2001.

[50] M. Jeszka-Skowron and A. Zgoła-Grześkowiak, "Analysis of Antioxidant Activity, Chlorogenic Acid, and Rutin Content of Camellia sinensis Infusions Using Response Surface Methodology Optimization," Food Analytical Methods, vol. 7, no. 10, pp. 2033-2041, 2014.

[51] I. Generalić, D. Skroza, J. Šurjak et al., "Seasonal variations of phenolic compounds and biological properties in sage (Salvia officinalis L.)," Chemistry \& Biodiversity, vol. 9, no. 2, pp. 441457, 2012.

[52] S. Tabarki, C. Aouadhi, K. Mechergui et al., "Comparison of Phytochemical Composition and Biological Activities of Rubus ulmifolius Extracts Originating from Four Regions of Tunisia," Chemistry \& Biodiversity, vol. 14, no. 1, Article ID e1600168, 2017.

[53] E. Lee, A. Shin, K.-W. Jeong et al., "Role of phenylalanine and valine10 residues in the antimicrobial activity and cytotoxicity of piscidin-1," PLoS ONE, vol. 9, no. 12, Article ID el14453, 2014.

[54] Z. Ali, S. R. Gilani, F. Jabeen, H. Hussain, H. Rehman, and I. Hussain, "Investigation of antibacterial activity of alanine and phenylalanine derived weinreb amides against different bacterial strains," Asian Journal of Chemistry, vol. 26, no. 20, pp. 7067-7068, 2014.

[55] F. Tian, C.-J. Chang, J. B. Grutzner, D. E. Nichols, and J. L. McLaughlin, "Robinlin: A novel bioactive homo-monoterpene from Robinia pseudoacacia L. (Fabaceae)," Bioorganic \& Medicinal Chemistry Letters, vol. 11, no. 19, pp. 2603-2606, 2001.

[56] A. Rosu, A. Bita, D. Calina, L. Rosu, O. Zlatian, and V. Calina, "Synergic antifungal and antibacterial activity of alcoholic extract of the species Robinia pseudoacacia L. (Fabaceae)," European Journal of Hospital Pharmacy: Science and Practice, vol. 19, no. 2, pp. 216.2-216, 2012.

[57] E.-S. Park, W.-S. Moon, M.-J. Song, M.-N. Kim, K.-H. Chung, and J.-S. Yoon, "Antimicrobial activity of phenol and benzoic acid derivatives," International Biodeterioration \& Biodegradation, vol. 47, no. 4, pp. 209-214, 2001.

[58] M. Khoury, D. Stien, N. Ouaini, V. Eparvier, N. A. Apostolides, and M. El Beyrouthy, "Chemical composition and antimicrobial activity of the essential oil of Ruta chalepensis L. growing wild in Lebanon," Chemistry \& Biodiversity, vol. 11, no. 12, pp. 19901997, 2014.

[59] I. Carev, M. Ruscic, M. Skocibusic, A. Maravic, S. SiljakYakovlev, and O. Politeo, "Phytochemical and Cytogenetic Characterization of Centaurea solstitialis L. (Asteraceae) from 
Croatia," Chemistry \& Biodiversity, vol. 14, no. 2, Article ID e1600213, 2017.

[60] Z. Y. Zhang, G. H. Dai, Y. Y. Zhuge, and Y. B. Li, "Protective effect of Robinia pseudoacacia Linnl extracts against cucumber powdery mildew fungus, Sphaerotheca fuliginea," Crop Protection, vol. 27, no. 6, pp. 920-925, 2008.

[61] A. E. Al-Snafi, "Chemical constituents and pharmacological effects of Citrulluscolocynthis," IOSR Journal of Pharmacy, vol. 6, pp. 57-67, 2013. 


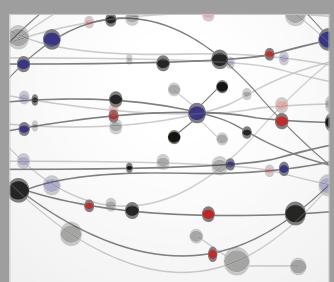

The Scientific World Journal
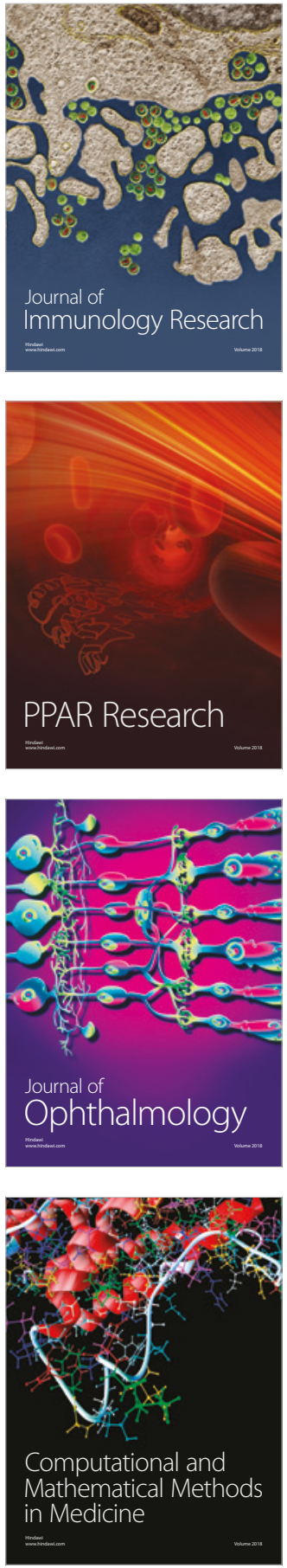

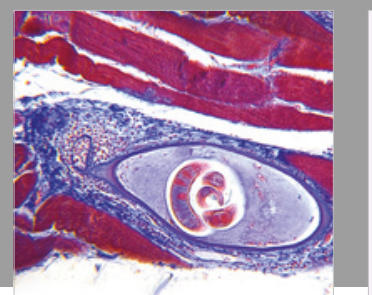

Gastroenterology Research and Practice

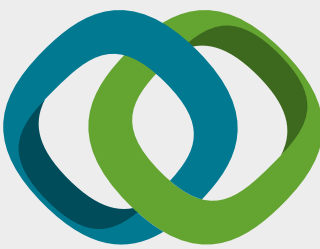

\section{Hindawi}

Submit your manuscripts at

www.hindawi.com
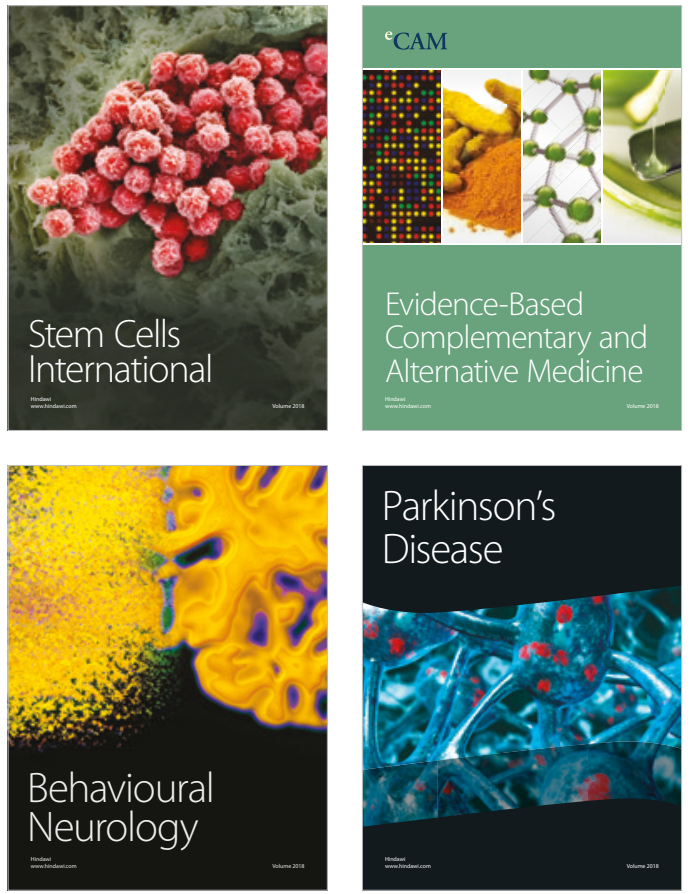

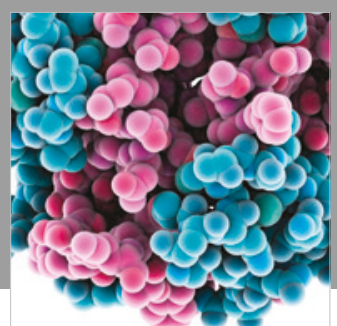

ournal of

Diabetes Research

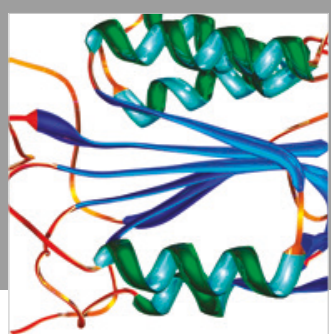

Disease Markers
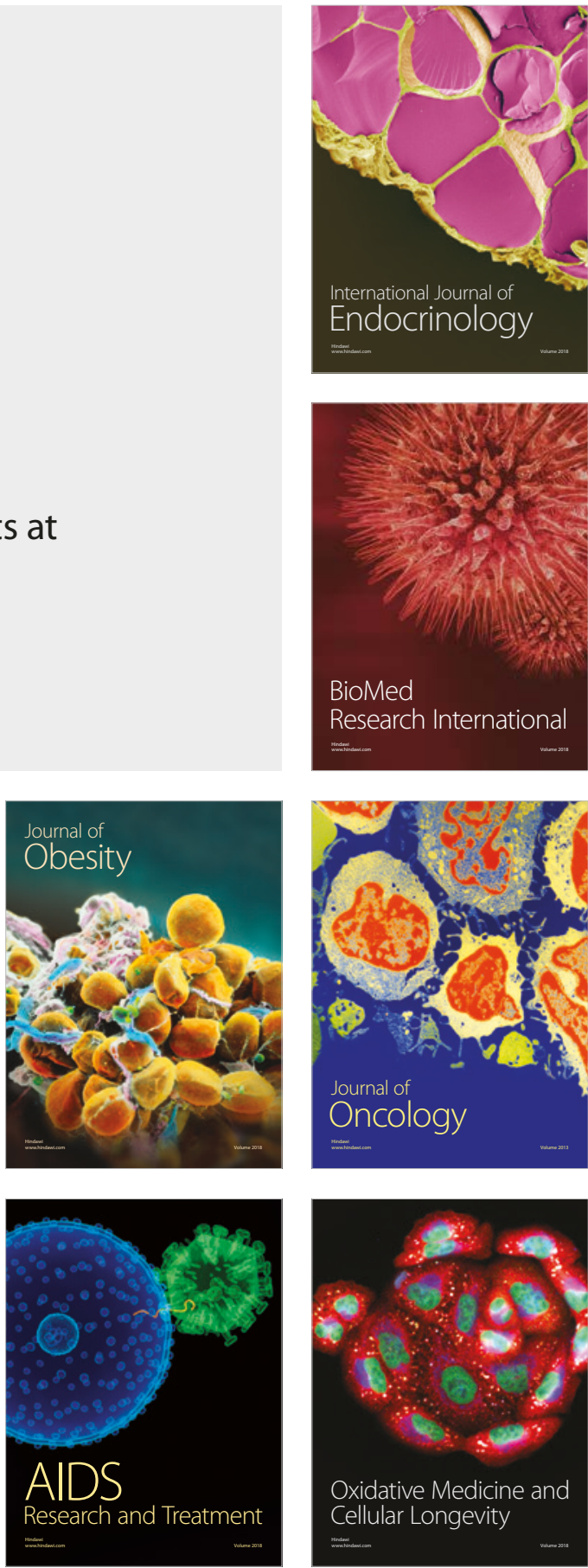